\title{
Effect of Hybrid Steel-Basalt Fiber on Behaviors of Manufactured Sand RPC and Fiber Content Optimization Using Center Composite Design
}

\author{
Yunlong Zhang, Jiahui Liu $\mathbb{D}^{D}$, Jing Wang, and Bin Wu \\ School of Transportation Science and Engineering, Jilin Jianzhu University, Changchun 130000, China \\ Correspondence should be addressed to Jiahui Liu; 15584787755@163.com
}

Received 4 September 2020; Revised 18 November 2020; Accepted 23 November 2020; Published 11 December 2020

Academic Editor: José Aguiar

Copyright (c) 2020 Yunlong Zhang et al. This is an open access article distributed under the Creative Commons Attribution License, which permits unrestricted use, distribution, and reproduction in any medium, provided the original work is properly cited.

\begin{abstract}
The mechanical properties and workability of manufactured sand reactive powder concrete (RPC) mixed with steel and basalt fibers were studied using the response surface method. The central composite design was used to explore the 7-day and 28-day compressive strength, flexural strength, and workability of different amounts of mixed fiber-manufactured sand RPC. Results showed that when the steel fiber content was less than $2.5 \%$, mixing basalt fibers can significantly improve the flexural strength and flexural-compressive ratio of RPC. The relationship equations of the two fibers with the 28-day compressive strength, flexural strength, and flexural-compressive ratio of the manufactured sand RPC were obtained through the response surface model. The model proved to be reliable according to the analysis of variance. The content of the two fibers was optimized by multiobjective optimization technology, and the optimal content of the mixed fiber-manufactured sand RPC under standard curing conditions was verified.
\end{abstract}

\section{Introduction}

Reactive powder concrete (RPC) is a high-density cement-based composite material with high strength, high durability, good stability, and broad application prospects developed in the 1990s $[1,2]$. The use of RPC in the structure can effectively reduce its size and weight while saving more resources. Existing studies mostly use quartz sand and river sand to prepare RPC; the use of manufactured sand to prepare RPC is still in its infancy [3]. Using manufactured sand instead of quartz sand can lower the cost. And if the river sand could be replaced by the manufactured sand, the damage to the river bed and dam could be lessened. Therefore, manufactured sand RPC has important research value. In order to improve the mechanical properties of RPC and reduce the brittleness caused by its high strength, various fibers are usually added to RPC [4-7]. However, there are few reports on the blending of fibers in manufactured sand RPC, and how to blend fibers in manufactured sand RPC and the ratio of fibers are the technical key to the application of manufactured sand in RPC. Therefore, the research on adding fiber to manufactured sand RPC is very important.

Currently, the researches on the steel fiber are developing faster than that of other fibers. The addition of steel fiber can significantly improve the tensile properties of RPC and hinder the development of cracks to improve the ductility and toughness of RPC [8-10]. A proper ratio of mixing steel fiber can replace part of steel bars in structures, thereby reducing the difficulty and cost of construction [11]. However, the strength of RPC will not continue to increase with the amount of steel fiber. Blindly increasing the fiber content not only increases the self-weight of the structure but also causes the poor workability of concrete because of the agglomeration of steel fiber [3]. Basalt fiber, as a new environmental-friendly material in the 21 st century, has excellent mechanical properties, corrosion resistance, high temperature resistance, and electrical insulation properties. In recent years, it has been widely used in the reinforcement of concrete materials [12]. Compared with steel fiber, basalt 
fiber has higher tensile strength, smaller size, and more fibers in the same volume. And the addition of basalt fiber improves the initial cracking strength of concrete under bending load, which effectively inhibits the generation of microcracks [13]. Basalt fiber has better workability when added to concrete, but its effect of enhancing the compressive strength is not as obvious as tensile strength and flexural strength [14]. Therefore, steel fiber and basalt fiber have a certain degree of synergy and complementarity in terms of size and reinforcement mechanism. So some scholars have mixed basalt fiber and steel fiber into ordinary concrete and found that it exhibits a good positive hybrid effect [15]. Compared with single blended fiber, the flexural strength of blended steel-basalt fiber is more significantly improved, but the compressive strength will be reduced when the blending fiber content is high [16]. Under appropriate blending amount, the shear strength, axial tensile strength, four-point bending strength, splitting tensile strength, and energy dissipation capacity could be improved significantly [17]. However, most of the studies are on the effect of steel-basalt fiber mixing on ordinary concrete. The interaction between steel-basalt fiber in manufactured sand RPC and how to acquire the best mixing effect has not been systematically analyzed. Therefore, the compressive strength and flexural strength of the steel-basalt fiber-manufactured sand RPC were tested to facilitate the preparation of manufactured sand RPC that meets actual engineering needs.

In summary, this article uses the content of steel fiber and basalt fiber as the influencing factors through the central composite design to study the influence of the interaction between steel fiber and basalt fiber on the mechanical properties and workability of manufactured sand RPC. Employing the response surface method, the compressive strength, flexural strength, and flexural-compressive strength ratio of manufactured sand RPC under the interaction of steel fiber and basalt fiber are analyzed, and a response surface model is established to obtain the relationship between the two fibers and the mechanical strength. The response surface fitting formula can be used to obtain the steel-basalt fiber content corresponding to the RPC of manufactured sand with different strengths, so as to prepare the manufactured sand RPC that can meet different requirements. The response surface method is used to optimize the design of steel-basalt fiber-manufactured sand RPC, and the results are verified by experiments, which provides the necessary theoretical basis for the promotion and application of manufactured sand RPC.

\section{Materials and Methods}

2.1. Raw Material. P.II52.5 cement by Jilin Yatai Cement (Changchun, China) was used for the test. The cement inspection report (Table 1) complies with the General Portland Cement Testing Standard (GB175-2007) [18]. Silica fume produced by Dongyue Silicone Material (Zibo, China), fly ash manufactured by Datang Second Thermal Power (Changchun, China), and S95-grade mineral powder produced by Longze Water Purification Materials
(Gongyi, China) were used. The test reports are presented in Tables 2-4. These materials were used in accordance with the technical specifications of the application of mineral admixtures (GB/T51003/2014) [19]. The superplasticizer used was an HSC polycarboxylic acid high-performance water-reducing agent produced by Borida Building Materials (Chongqing, China). The test report is shown in Table 5. The fine aggregate was made from manufactured sand produced by Jiusheng Industry (Changchun, China), and a photo is presented in Figure 1. The sand screening test results are provided in Table 6, and according to the Standard for Technical Requirements and Test Method of Sand and Crushed Stone for Ordinary Concrete (JGJ 522006) [20], the manufactured sand distribution is shown in Figure 2. The steel fibers were made from copper-plated steel fibers manufactured by Ruke Steel Fiber Industry (Yongkang, China). The specifications and performance indices are shown in Table 7 . Figure 3 presents a picture of the steel fibers. The basalt fibers were made from copperplated steel fibers produced by Anjie Composite Material Factory (Haining, China). The specifications and performance indices are listed in Table 8 , and a picture is shown in Figure 4.

2.2. Test Preparation and Curing. First, the cement, silica fume, fly ash, mineral powder, and manufactured sand were poured into a mixer and dry mixed for $2 \mathrm{~min}$. Second, as mixing continued, steel and basalt fibers were sprinkled through a sieve. When the fibers were added, they scattered after 2 min of dry mixing. Third, a mixture of $80 \%$ superplasticizer and water was added slowly and stirred for $4 \mathrm{~min}$. Finally, the remaining superplasticizer agent was added and stirred for $2 \mathrm{~min}$.

In this test, the curing method was standard curing (temperature: $20^{\circ} \mathrm{C} \pm 2{ }^{\circ} \mathrm{C}$, humidity: $95 \%$ ). After the RPC was installed, the specimens were placed immediately in the curing room. After $24 \mathrm{~h}$, the specimens were separated from the mold and placed once again in the curing room for curing until the test days, as shown in Figure 5.

\subsection{Testing Procedure}

2.3.1. Mix Proportion. The mix proportion used in the experiment is shown in Table 9. The mix proportion is the optimal mix ratio determined by the orthogonal test of Zhong et al. [3], taking the water-binder ratio, sand-binder ratio, silica fume, and fly ash as factors and analyzing compressive strength. The amount of HSC polycarboxylic acid superplasticizer added in this experiment was $1.2 \%$ of the cementing material quality.

2.3.2. Testing Program. According to the GB/T31387-2015 [21], a $100 \mathrm{~mm} \times 100 \mathrm{~mm} \times 100 \mathrm{~mm}$ cube specimen was selected as the test specimen for pressure resistance. An SYE3000B hydraulic press (Hydraulic Press of New Testing Machine Co., Ltd., Changchun, China) was used for loading. The loading rate for the compressive test was kept between 
TABLE 1: Physical and chemical properties of cement.

\begin{tabular}{|c|c|c|c|}
\hline \multicolumn{2}{|c|}{ Properties } & \multirow{2}{*}{$\begin{array}{c}\text { Standard value } \\
\geq 300\end{array}$} & \multirow{2}{*}{$\frac{\text { Actual value }}{363}$} \\
\hline \multirow{3}{*}{ Physical properties } & Specific surface area $\left(\mathrm{m}^{2} / \mathrm{kg}\right)$ & & \\
\hline & Initial set $(\min )$ & $\geq 45$ & 128 \\
\hline & Final set (min) & $\leq 390$ & 183 \\
\hline \multirow{2}{*}{ Compressive strength } & 3 days $(\mathrm{MPa})$ & $\geq 23.0$ & 31.5 \\
\hline & 7 days $(\mathrm{MPa})$ & $\geq 52.5$ & 59.6 \\
\hline \multirow{2}{*}{ Flexural strength } & 3 days $(\mathrm{MPa})$ & $\geq 4.0$ & 6.1 \\
\hline & 7 days $(\mathrm{MPa})$ & $\geq 7.0$ & 9.0 \\
\hline \multirow{6}{*}{ Chemical properties } & Stability & Qualified & Qualified \\
\hline & Loss on ignition (\%) & $\leq 3.5$ & 1.27 \\
\hline & $\mathrm{MgO}(\%)$ & $\leq 5.0$ & 0.79 \\
\hline & $\mathrm{SO}_{3}(\%)$ & $\leq 3.5$ & 2.40 \\
\hline & Insolubles (\%) & $\leq 1.5$ & 1.01 \\
\hline & $\mathrm{Cl}^{-}(\%)$ & $\leq 0.06$ & 0.009 \\
\hline
\end{tabular}

TABle 2: Physical and chemical properties of silica fume.

\begin{tabular}{lccc}
\hline & Properties & Standard value & Actual value \\
\hline \multirow{2}{*}{ Physical properties } & Specific surface area $\left(\mathrm{m}^{2} / \mathrm{kg}\right)$ & $\geq 15$ & 20 \\
& Pozzolanic activity index $(\%)$ & $\geq 85$ & 116 \\
\hline & $\mathrm{SiO}_{2}(\%)$ & $\geq 85.0$ & 95 \\
Chemical properties & Loss ignition (\%) & $\leq 6.0$ & 1.95 \\
& $\mathrm{Cl}^{-}(\%)$ & $\leq 0.02$ & 0.02 \\
& Moisture content (\%) & $\leq 3.0$ & 1.2 \\
& Water demand ratio $(\%)$ & $\leq 125$ & 118 \\
\hline
\end{tabular}

TABle 3: Chemical properties of fly ash.

\begin{tabular}{cccc}
\hline & Properties & Standard value & Actual value \\
\hline & Water demand ratio (\%) & $\leq 95$ & 91 \\
& Loss on ignition (\%) & $\leq 5.0$ & 2.8 \\
& Moisture content (\%) & $\leq 1.0$ & 0.1 \\
Chemical properties & $\mathrm{SO}_{3}(\%)$ & $\leq 3.0$ & 2.0 \\
& $\mathrm{CaO}_{3}(\%)$ & $\leq 1.0$ & 0.16 \\
& $\mathrm{MgO}(\%)$ & $\leq 5.0$ & 1.08 \\
& $\mathrm{Cl}^{-}(\%)$ & & 0.01 \\
\hline
\end{tabular}

TABle 4: Physical and chemical properties of mineral powder.

\begin{tabular}{lccc}
\hline & Properties & Standard value & Actual value \\
\hline & Specific surface area $\left(\mathrm{m}^{2} / \mathrm{kg}\right)$ & $\geq 400$ & 429 \\
Physical properties & Liquidity ratio $(\%)$ & $\geq 95$ & 102 \\
& Density (\%) & $\geq 2.8$ & 2.8 \\
\hline & Moisture content (\%) & $\leq 1.0$ & 1.0 \\
Chemical properties & Loss on ignition (\%) & $\leq 3.0$ & 3.0 \\
& Pozzolanic activity index (\%) & 28 days $\geq 75$ & 83 \\
\hline
\end{tabular}

1.2 $\mathrm{MPa} / \mathrm{s}$ and $1.4 \mathrm{MPa} / \mathrm{s}$. The flexural strength test utilized a $100 \mathrm{~mm} \times 100 \mathrm{~mm} \times 400 \mathrm{~mm}$ prism specimen and used a WAW-1000B electrohydraulic servo universal material testing machine (Hydraulic Press of New Testing Machine Co., Ltd., Changchun, China) for loading. The loading rate was maintained at approximately $0.08 \mathrm{MPa} / \mathrm{s}$ and $0.1 \mathrm{MPa} / \mathrm{s}$. The mean values of the three measured compressive strength and flexural strength values were taken as the test results. Slump and slump flow were measured according to GB/ T50080-2002 [22]. 
TABle 5: Physical and chemical properties of superplasticizer.

\begin{tabular}{|c|c|c|c|}
\hline \multicolumn{2}{|c|}{ Properties } & Standard value & Actual value \\
\hline \multirow{3}{*}{ Physical properties } & Water reduction rate & $\geq 25$ & 28 \\
\hline & Gas content (\%) & $\leq 6.0$ & 2.9 \\
\hline & Bleeding rate $(\%)$ & $\leq 60$ & 37 \\
\hline \multirow{3}{*}{ Chemical properties } & $\mathrm{Cl}^{-}(\%)$ & $\leq 0.1$ & 0.02 \\
\hline & $\mathrm{OH}^{-}(\%)$ & $\leq 3$ & 2 \\
\hline & $\mathrm{Na}_{2} \mathrm{SO}_{4}$ & $\leq 0.5$ & 0.2 \\
\hline
\end{tabular}

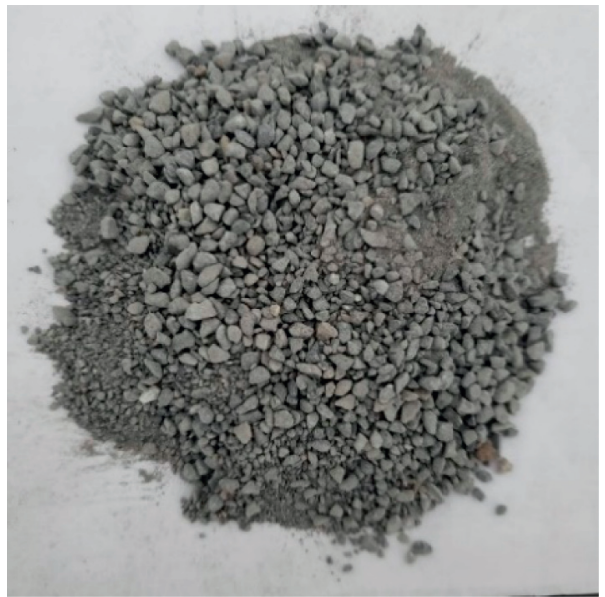

FIgURE 1: Manufactured sand.

TABLE 6: Manufactured sand screening test results.

\begin{tabular}{|c|c|c|c|c|c|c|}
\hline \multirow{2}{*}{ Properties } & \multicolumn{5}{|c|}{ Sieve size $(\mathrm{mm})$} & \multirow{2}{*}{ Sieve bottom } \\
\hline & 2.36 & 1.18 & 0.6 & 0.3 & 0.15 & \\
\hline Sieve residue (g) & 85 & 145 & 107 & 55 & 92.5 & 15.5 \\
\hline Submeter (\%) & 17 & 29 & 21.4 & 11 & 18.5 & 3.1 \\
\hline Cumulative (\%) & 17 & 46 & 67.4 & 78.4 & 96.9 & 100 \\
\hline
\end{tabular}

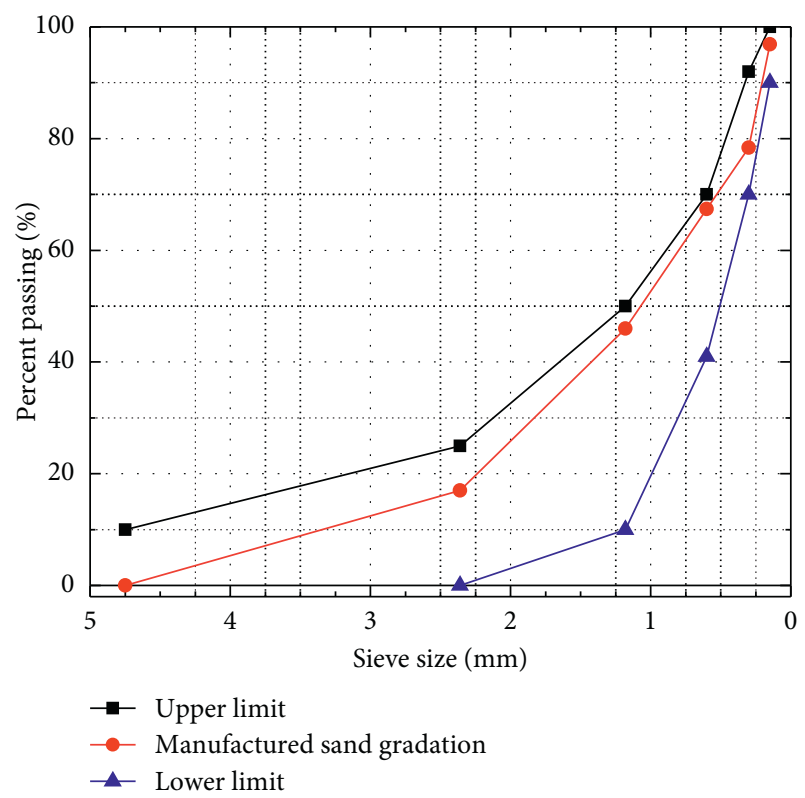

FIGURE 2: Gradation of manufactured sand used in this study.
TABLe 7: Physical properties of steel fibers.

\begin{tabular}{lcccc}
\hline Index & $\begin{array}{c}\text { Diameter } \\
(\mathrm{mm})\end{array}$ & $\begin{array}{c}\text { Length } \\
(\mathrm{mm})\end{array}$ & $\begin{array}{c}\text { Aspect } \\
\text { ratio }\end{array}$ & $\begin{array}{c}\text { Tensile strength } \\
(\mathrm{MPa})\end{array}$ \\
\hline $\begin{array}{l}\text { Unit } \\
\text { value }\end{array}$ & 0.2 & 13 & 65 & 2850 \\
\hline
\end{tabular}

2.3.3. CCD. The RSM is a combination of statistical and mathematical techniques, which is widely used in various fields for modeling and analysis. Compared with other experimental methods, the advantage of the RSM is that the relationship between response and various factors can be found through a small number of experiments [23]. In this study, the CCD in the RSM was adopted. The CCD is the most common experimental design method in RSM research [24]. The specific process involves obtaining a combination of numerous test data through the CCD for the test to determine the response value and establishing the functional relationship between the influencing parameter and response value through an undetermined coefficient method, thereby attaining a highly accurate response surface model. In addition, the analysis of variance (ANOVA) was used to 


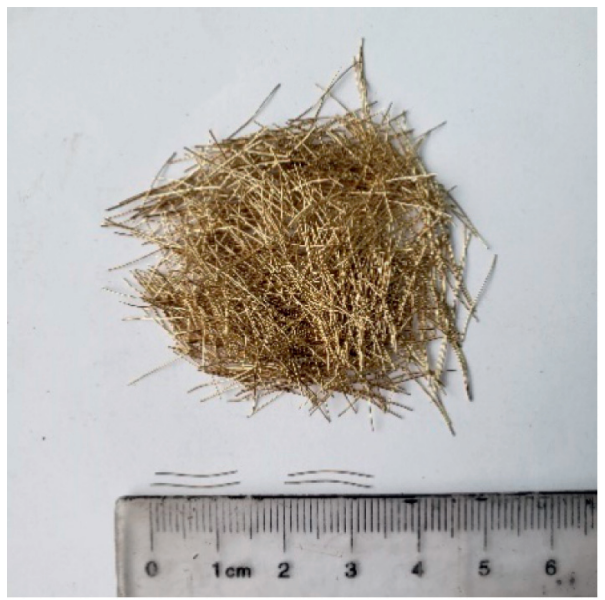

Figure 3: Steel fibers.

TABLe 8: Physical properties of basalt fibers.

\begin{tabular}{lcccccc}
\hline Index & Length $(\mathrm{mm})$ & Diameter $(\mathrm{mm})$ & Density $\left(\mathrm{g} / \mathrm{cm}^{3}\right)$ & Elastic modulus $(\mathrm{GPa})$ & Tensile strength $(\mathrm{MPa})$ & Elongation at fracture $(\%)$ \\
\hline Unit value & 12 & $7-15$ & 2.65 & $91 \sim 110$ & $3000 \sim 4800$ & $1.5 \sim 3.2$ \\
\hline
\end{tabular}

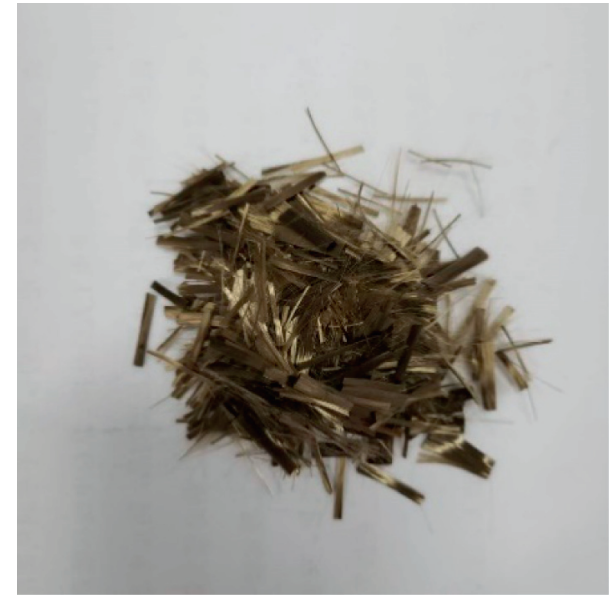

Figure 4: Basalt fibers.

examine the interaction between the various variables and impact on the response and to optimize the model to find the optimal solution.

Each influencing factor in the CCD was set to five levels. The test consisted of three parts, that is, the factorial test at the cube point, the repeated test at the center point, and the star point test at the axial point. The distribution of twofactor CCD test points is shown in Figure 6 [25], with $2^{k}$ factorial points, where $k$ represents the number of factors and $2 k$ represents axial points. The axial point distance from the center point is $2^{k / 4}$. The center point in the CCD is determined by the average value of the factorial point. The number of experiments required for the CCD is determined by the following equation [26]:

$$
N=2^{k}+2 k+C_{P}
$$

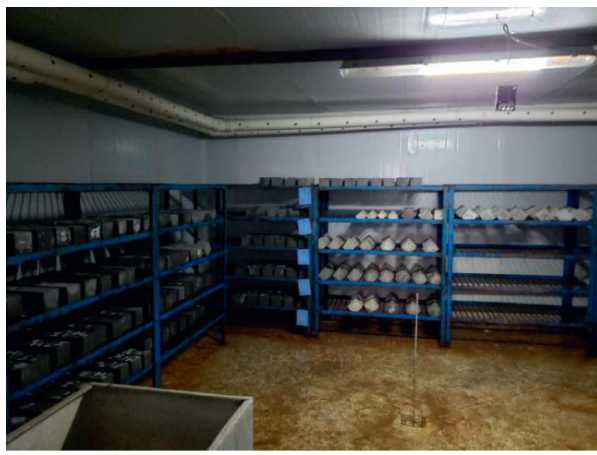

FIgURE 5: Standard curing.

where $k$ is the number of factors and $C_{p}$ is the number of central points.

A quantitative mathematical relationship (quadratic polynomial linear equation) was obtained by establishing the response surface model to reflect the relationship between the factors and response, and the optimal condition of the response can be determined, as shown in the following equation:

$$
y=\beta_{0}+\sum_{i=1}^{k} \beta_{i} x_{i}+\sum_{i=1}^{k} \beta_{i i} x_{i}^{2}+\sum_{i} \sum_{j} \beta_{i j} x_{i} x_{j}+\varepsilon
$$

where $y$ is the predictive response, $x_{i}$ and $x_{j}$ are the code values of factor variables, $i$ is the linear coefficient, $j$ is the quadratic coefficient, $\beta$ is the regression coefficient, $k$ is the number of factors for experimental research and optimization, and $\varepsilon$ is the random error $[24,25]$.

In this study, the Design-Expert $8^{\circledR}$ software was used for the CCD, mathematical modeling, and variable analysis and optimization. In addition, ANOVA was employed to study 
TABLE 9: Mix proportion.

\begin{tabular}{lcccccc}
\hline Water/binder ratio & Cement (\%) & Silica fume (\%) & Fly ash (\%) & Mineral powder (\%) & Sand/binder ratio & Superplasticizer (\%) \\
\hline 0.18 & 62 & 13 & 20 & 5 & 0.7 & 1.2 \\
\hline
\end{tabular}

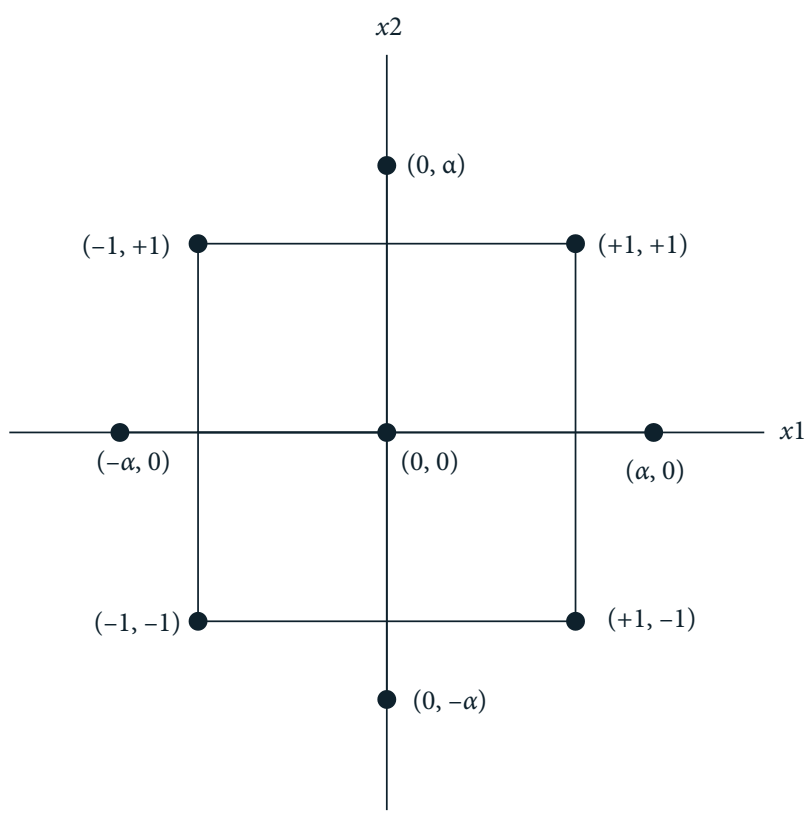

Figure 6: Two-factor CCD.

the interaction between the variables and the influence of each parameter on the response. Steel fiber content $(A)$ and basalt fiber content $(B)$ were taken as factor variables, and the unit was percentage. The 28-day compressive strength (R1), 28day flexural strength (R2), and 28-day flexural-compressive ratio (R3) were the responses. According to the literature, the selected factor range is $1 \%-4 \%[3,17]$ for steel fibers and $0-0.35 \%$ for basalt fibers $[12,15,17]$. Table 10 shows the code values of five levels and the responses of the two factors. The high and low levels of each factor were coded as -1 and +1 , the center point was coded as 0 , and the axis point was coded as $-\alpha$ and $+\alpha$. In addition, $\alpha$ was 1.414 under the two factors.

The two-factor five-level CCD test design consisted of four sets of factorial tests, four sets of star point tests, and five sets of center repeat tests. The factor variable code values and test results of 13 experimental CCD groups in this study are shown in Table 11, in which $\mathrm{H} 9-\mathrm{H} 13$ are five repeated center test groups for evaluating the stability of the model. The H0 group without fibers but with the same mix ratio was added as the reference group.

\section{Results and Discussion}

3.1. Workability of RPC. Workability is significantly reduced after the RPC blending. In the slump test, the overlap of the hybrid fibers increases the integration of the RPC. Filling the slump cylinder during the tamping process is difficult. The specific surface area of the steel and basalt fibers is large, and the basalt fibers have a rough surface and high friction coefficient, which increase internal friction resistance and
TABLE 10: Code levels.

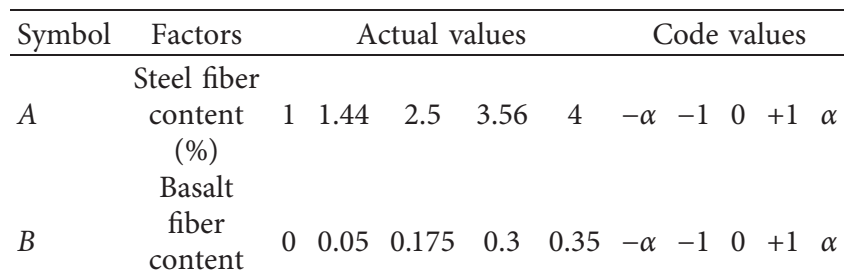

(\%)

worsen the fluidity of the mixture. A large amount of cement paste is attached to the surface of the hybrid fibers, and the cement paste wrapped around the manufactured sand is reduced [8], thereby increasing the viscosity of the mixture and decreasing workability. With the same amount of steel fibers $(A)$, slump is slightly reduced as the amount of the basalt fibers $(B)$ increases. This result is caused by the existence of hybrid fiber which hinder the relative slip between the particles. Moreover, owing to their obvious hydrophilicity, the basalt fibers are mixed into the mixture and dispersed into a large number of very fine flocculent fiber filaments, which absorb part of the free water, thereby weakening the fluidity of the manufactured sand RPC.

\subsection{Analysis of Mechanical Properties of Steel-Basalt Fiber-Manufactured Sand RPC}

3.2.1. Compressive Strength. The 7-day and 28-day compressive strength of 14 sets of cube specimens are tested, and the test results are presented in Figure 7. Compared with the reference group, the compressive strength of the sand RPC mixed with hybrid fibers is significantly better. The addition of hybrid fibers improves integrity, and the bonding force between the hybrid fibers and RPC matrix plays a satisfactory role in enhancing compressive strength during the loading process. In the compression process, the sound of pulling fibers can be heard in the RPC test block. Moreover, the RPC test block does not burst like the fiberless RPC but gradually drops fragments and retains a relatively complete shape after the test. When the test block is removed, hybrid fiber bridges are observed in the concrete matrix along cracks, as shown in Figure 8. The steel fiber content of the $\mathrm{H} 8$, central (H9-H13), and $\mathrm{H} 7$ groups is $2.5 \%$, but the basalt fiber content differs. Compared with the reference group, the 7-day compressive strength of the three groups increases by $19.89 \%, 29.11 \%$, and $16.72 \%$, and their 28 -day compressive strength increases by $29.61 \%, 31.64 \%$, and $24.62 \%$. When the steel fiber content is $2.5 \%$, with an increase in the basalt fiber content, the 7-day and 28-day compressive strength show an initial increasing and then decreasing trend. Compared with the reference group, the 7-day compressive strength of the $\mathrm{H} 3$ and $\mathrm{H} 1$ groups increases by $4.66 \%$ and $-2.49 \%$, respectively, and the 28-day compressive strength increases by 


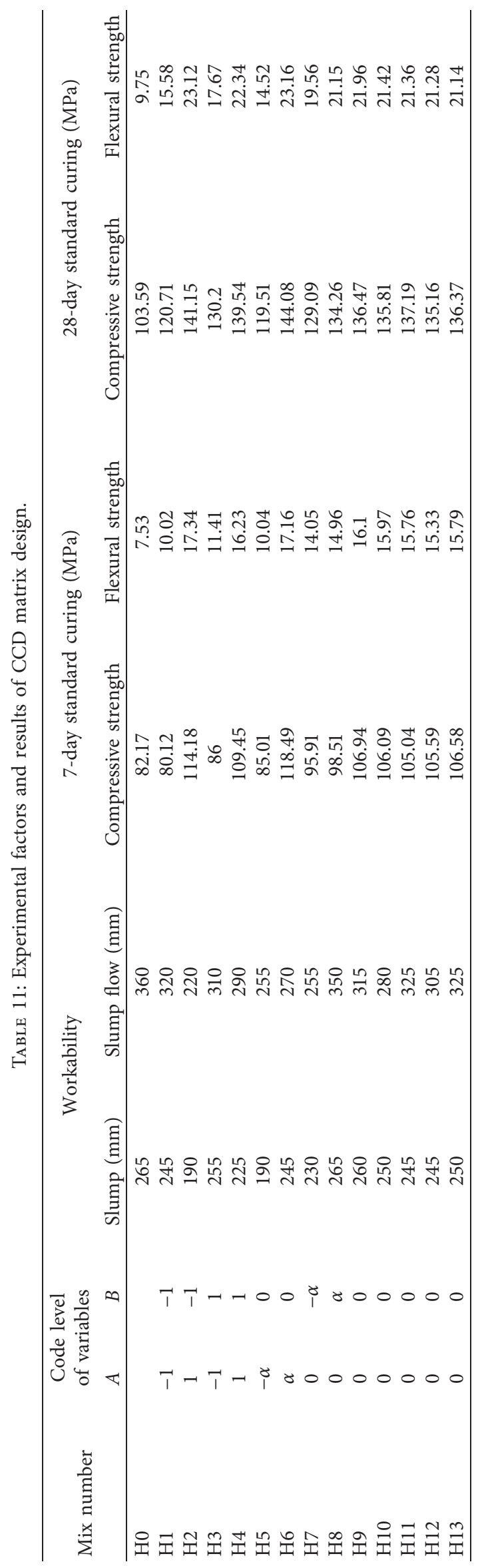




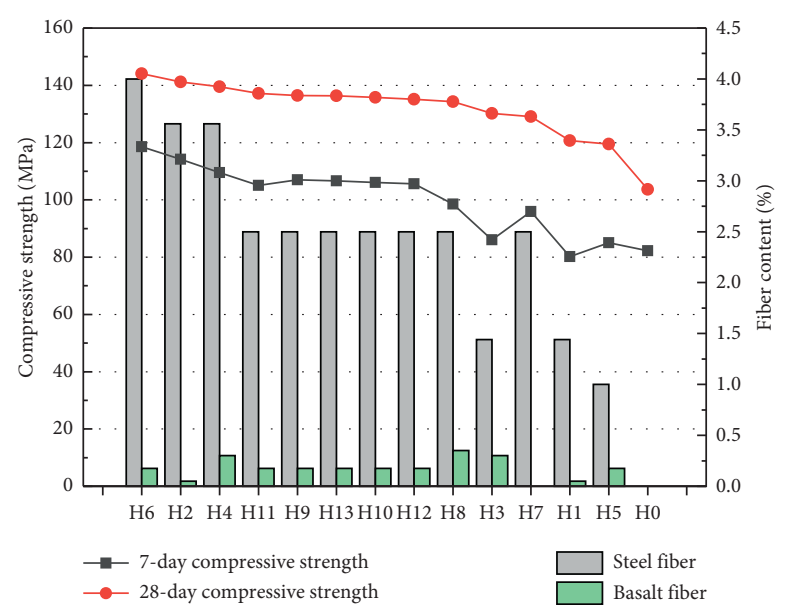

Figure 7: Compressive test result.

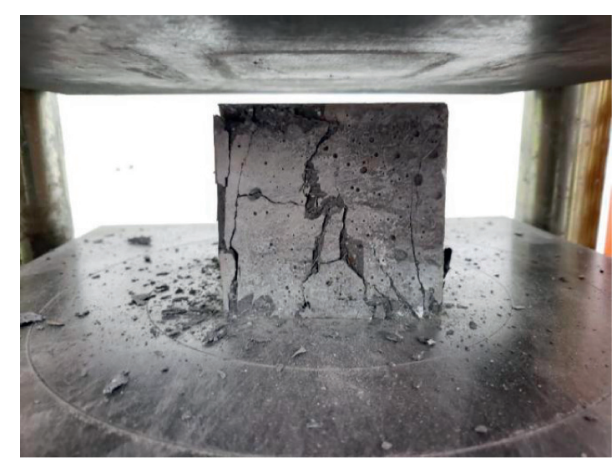

FIGURE 8: Failure condition of compressive specimens.

$25.69 \%$ and $16.53 \%$, respectively. The steel fiber content of both groups is $1.44 \%$, but the basalt fiber content of the H3 group increases by $0.25 \%$ compared with that of the $\mathrm{H} 1$ group, thereby showing a relatively higher compressive strength. Compared with the reference group, the 7-day compressive strength of the $\mathrm{H} 4$ and $\mathrm{H} 2$ groups increases by $33.21 \%$ and $38.96 \%$, respectively, and the 28 -day compressive strength increases by $34.7 \%$ and $36.26 \%$, respectively. The basalt fiber content of the $\mathrm{H} 4$ group increases by $0.25 \%$ compared with that of the $\mathrm{H} 2$ group, but its 7-day and 28day compressive strength decrease. It can be found that when the content of steel fiber is small, with the increase of the content of basalt fiber, the compressive strength of $7 \mathrm{~d}$ and $28 \mathrm{~d}$ are significantly improved, and when the steel fiber amount is high, the effect of the basalt fibers on the compressive strength of the manufactured sand RPC is very small. This finding is observed because the size of the basalt fibers is smaller than that of the steel fibers. When the steel fiber amount is small, the appropriate amount of basalt fibers can be distributed evenly among the steel fibers to play a bridging role and inhibit the expansion of cracks. When the steel fiber amount is high, the incorporation of basalt fibers leads to fiber agglomeration, an increase in internal defects, and a reduction of compressive strength. In summary, compressive strength is not consistently enhanced with the increase of hybrid fiber content, and proper fiber content will exert a positive mixing effect. Excessive amounts of fiber will only waste resources, and strength improvement is not obvious.

3.2.2. Flexural Strength. A total of 84 $100 \mathrm{~mm} \times 100 \mathrm{~mm} \times 400 \mathrm{~mm}$ prism samples from the 14 groups are tested for their 7-day and 28-day flexural strength. The flexural strength test results are shown in Figure 9. Compared with the nonfiber RPC, the flexural strength of the mixed RPC is improved obviously, because the main factor affecting flexural strength is the bonding force between the fibers and the matrix. In the loading process, because the fibers demonstrate roughness and unevenness, the fibers slip with the matrix under tension and produce adhesion stress, which plays a bridging role and hinders the development of cracks [8], thereby substantially enhancing flexural strength. Given that the RPC hydration reaction at 7 days is incomplete and the bond between the fibers and the matrix is not at its maximum, pulling the fibers out during the bending resistance experiment is easy. However, after 28 days, the hydration reaction is complete and the bond between the fibers and the matrix is satisfactory, thereby considerably increasing the bending strength compared with that at 7 days. As shown in Figure 10, the antibending specimen demonstrates obvious deformation during compression. First, several microcracks appear at the bottom area between the two loading heads, and the main crack gradually expands, with debris observed in the crack gap. During the test, the sound of fiber extraction can be heard, and the cracks extend to achieve maximum flexural strength after a certain degree. The steel fibers in the cracks are extracted from the RPC matrix, and the basalt fibers are mostly pulled. As shown in Figure 9, the $\mathrm{H} 3$ group has the same steel fiber content of $1.44 \%$ as the $\mathrm{H} 1$ group, but the basalt content is $0.25 \%$ higher. Compared with the reference group, the 7-day flexural strength of the two groups increases by $51.53 \%$ and $33.07 \%$, and the 28 -day flexural strength increases by $81.23 \%$ and $59.79 \%$. The steel fiber content of the H7, central (9-13), and H8 groups is $2.5 \%$, and the basalt fiber content is $0 \%, 0.175 \%$, and $0.35 \%$, respectively. Compared with the reference group, the 7-day flexural strength of the three groups increases by $86.59 \%$, $109.3 \%$, and $98.67 \%$, and the 28 -day flexural strength increases by $100.62 \%, 119.08 \%$, and $116.92 \%$. It can be seen that when the steel fiber content is small, the increase of basalt fiber content has a good increase in flexural strength. The 7-day flexural strength of the $\mathrm{H} 4$ and $\mathrm{H} 2$ groups increases by $115.54 \%$ and $130.28 \%$, respectively, compared with that of the reference group, and the 28-day flexural strength increases by $129.13 \%$ and $137.13 \%$, respectively. The steel fiber content of the $\mathrm{H} 4$ and $\mathrm{H} 2$ groups is $3.56 \%$, but as the basalt fiber content increases, flexural strength decreases. When the steel fiber content is excessive, the addition of basalt fibers will not increase the flexural strength of the manufactured sand RPC. This finding is observed because the steel fibers form a network structure in the mixture, whereas the basalt fibers are small in volume but large in quantity. The appropriate amount of basalt fibers is scattered 


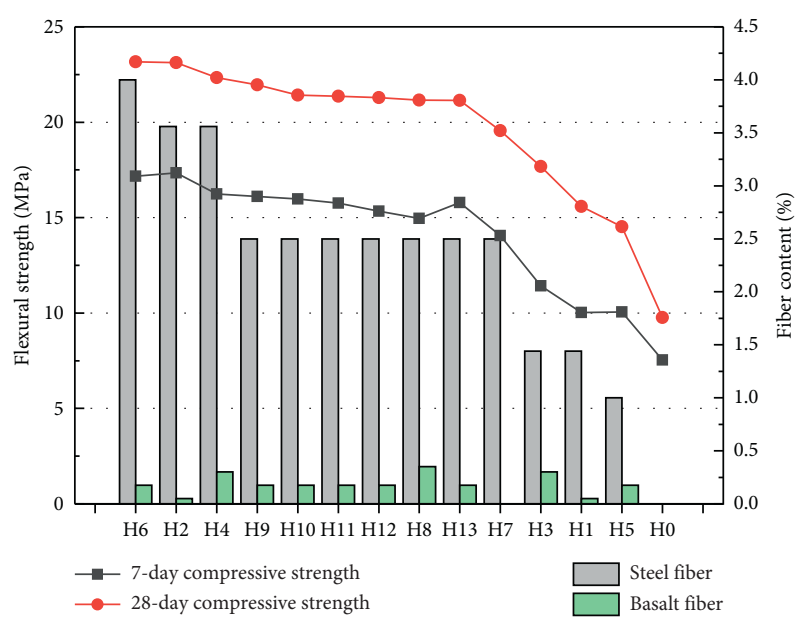

FIgURE 9: Flexural test results.

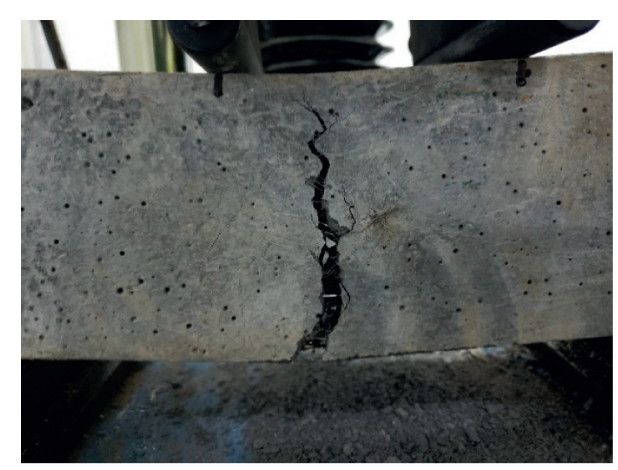

FIgURE 10: Failure condition of flexural specimens.

among the steel fibers, which helps the steel fibers pull and increases the probability of bridging the inner cracks of the RPC. However, when the steel fibers increase further, they will cross into the group with basalt fibers, the dispersion of the hybrid fibers in the matrix will not be uniform, the contact area with the cement mortar will be reduced, and the adhesion between the fibers and the matrix will be weakened, thereby resulting in the reduction of flexural strength. Thus, when the manufactured sand RPC steel fiber content is small, the influence of increased basalt content on flexural strength is obvious. When the steel fiber content is too high, the negative hybrid effect will occur when the basalt fiber content is likewise excessive.

3.2.3. Flexural-Compressive Ratio. Flexural-compressive ratio is the ratio of concrete flexural strength to compressive strength, used as a parameter to test the relationship between concrete compressive strength and flexural strength, the degree of influence on the two kinds of strength after mixing fiber can be seen by the flexuralcompressive ratio; that is, when the flexural strength is increased significantly, the flexural-compressive ratio will increase. But if the compressive strength is increased more significantly, and the flexural-compressive ratio will decrease. The 7-day and 28-day flexural-compressive ratios in this experiment are shown in Figure 11, and the 28-day flexural-compressive ratio is generally higher than the 7day flexural-compressive ratio. The $\mathrm{H} 3$ group has $0.25 \%$ more basalt content than the $\mathrm{H} 1$ group, and the steel fiber content of both groups is $1.44 \%$. The 7 -day flexuralcompressive ratio of the $\mathrm{H} 3$ and $\mathrm{H} 1$ groups increases by $44.76 \%$ and $36.57 \%$, respectively, and the 28 -day flexuralcompressive ratio increases by $44.31 \%$ and $37.19 \%$, respectively, compared with those of the reference group. The steel fiber content of the H7, central (9-13), and H8 groups is $2.5 \%$, and the basalt fiber content is $0 \%, 0.175 \%$, and $0.35 \%$, respectively. Compared with the reference group, the 7-day flexural-compressive ratio of the three groups increases by $59.93 \%, 62.45 \%$, and $68.12 \%$, and their 28-day flexural-compressive ratio increases by $61 \%$, $66.52 \%$, and $67.38 \%$, and the mixed basalt fiber will increase the flexural-compressive ratio. The proportion of the $\mathrm{H} 8$ group is $0.25 \%$ higher than that of the central group (9-13), and the flexural-compressive ratio changes slightly. Therefore, when the steel fiber content is small, the appropriate basalt fiber mixture can significantly improve the flexural-compressive ratio of the manufactured sand RPC. The main reason for this finding is because the basalt fibers play a small role in the compression process, and the basalt fibers along the length of the specimen are evenly distributed between the steel fibers in the bending test and play a bridging role with the steel fibers throughout the bending process. In addition, the basalt fibers assist in pulling the manufactured sand RPC, thereby helping it play a substantial role. Thus, the manufactured sand RPC mixed with steel-basalt fibers has a higher flexuralcompressive ratio than the manufactured sand RPC with steel fibers. The steel fiber amount of the $\mathrm{H} 4$ and $\mathrm{H} 2$ groups is $3.56 \%$, but the basalt fiber amount of the $\mathrm{H} 4$ group increases by $0.25 \%$ compared with that of the $\mathrm{H} 2$ group. However, the 28-day flexural-compressive ratio is reduced. Therefore, when the steel fiber content is too high, the addition of basalt fibers has a negative mixing effect on the flexural-compressive ratio. According to the aforementioned findings, when the steel fiber content is large, the addition of basalt fibers has little influence on the flexural strength of the manufactured sand RPC. Thus, the bending pressure ratio does not increase. The 28-day flexural-compressive ratio of ordinary concrete is generally between $7 \%$ and $8 \%$ [27], whereas the 28 -day flexuralcompressive ratio of the steel-basalt fiber-manufactured sand RPC is between $12 \%$ and $16 \%$. In other words, the steel-basalt fiber mixing enhanced RPC's flexural strength more obviously than its compressive strength. By selecting the appropriate flexural-compressive ratio, the road flexural strength could be effectively improved, which is of great significance to road engineering.

\subsection{Establishment and Analysis of Response Surface Model}

3.3.1. Establishment and Verification of RSM. In this study, three quadratic polynomial models of 28-day compression strength (R1), 28-day flexural strength (R2), and 28-day 


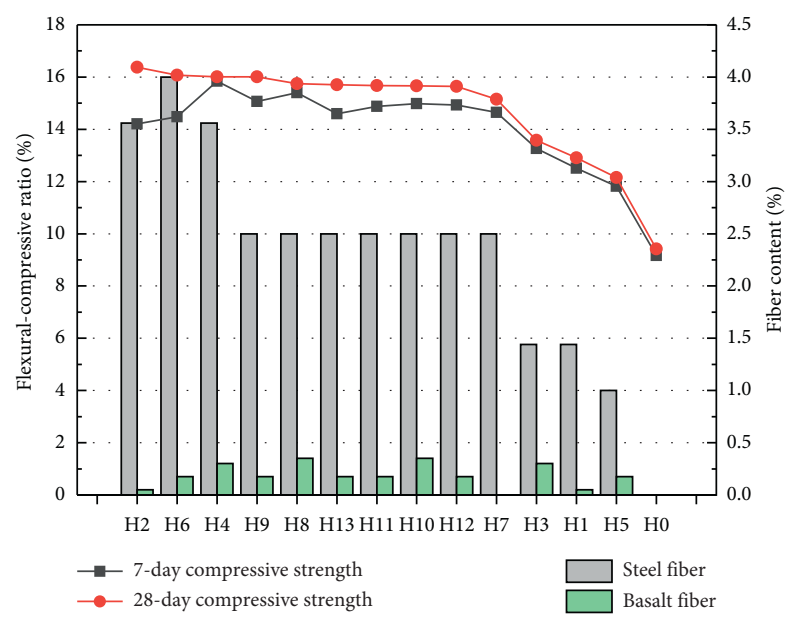

FIGURE 11: Flexural-compressive ratio results.

flexural-compressive ratio (R3) are established using the Design-Expert $10^{\circledR}$ software based on multiple regression analysis, as shown in (3)-(5). The models are generated from actual values, and the confidence level is maintained at $5 \%$ statistical significance to evaluate and verify the models. Through ANOVA, the interaction and relationship between the steel fiber content $(A)$, the basalt fiber content $(B)$, and responses R1, R2, and R3 are obtained, and the accuracy of the models is verified according to statistical parameters. The results of the ANOVA are shown in Table 12. When the $P$ value of the parameter is less than 0.05 , it is significant, and the parameter items with $P$ value $>0.05$ are removed to improve the model significance. Table 12 shows that the $P$ values of the three models are $<0.05$, thereby indicating that they have statistical significance at the $5 \%$ significance level. In addition, lack of fit can be used to measure the degree of fit between the models and the data. Contrary to the $P$ value of the parameter, when the lack of fit $(P<0.05)$ indicates that the fitting difference is large, an insignificant lack of fit $(P>0.1)$ is what we want, and the insignificant fitting is unsatisfactory. The lack of fit of the three models, that is, R1, R2, and R3, is not significant, thereby indicating that they can better reflect the relationship between the factors and responses.

$$
\begin{aligned}
\mathrm{R} 1= & 136.20+8.07 \cdot A+1.90 \cdot B-2.77 \cdot A \cdot B \\
& -1.91 \cdot A^{2}-1.97 \cdot B^{2}, \\
\mathrm{R} 2= & 21.43+3.05 \cdot A+0.4448 \cdot B-0.7175 \cdot A \cdot B \\
& -1.28 \cdot A^{2}-0.5185 \cdot B^{2}, \\
\mathrm{R} 3= & 15.74+1.43 \cdot A+0.1436 \cdot B-0.26 \cdot A \cdot B \\
& -0.828 \cdot A^{2}-0.158 \cdot B^{2} .
\end{aligned}
$$

The statistical results of variance show that the $R^{2}$ of $\mathrm{R} 1$, $\mathrm{R} 2$, and R3 is $0.9872,0.9943$, and 0.9928 , respectively, as shown in Table 13. $R^{2}$ is the absolute coefficient that is used to measure the reliability of a model. The closer the $R^{2}$ value to 1 , the more reliable the model. The $R^{2}$ value of the three models is significantly close to 1 , which further indicates their quality. Meanwhile, the predicted $R^{2}(0.9289,0.9836$, $0.9733)$ and adjusted $R^{2}(0.9780,0.9903,0.9877)$ of the three models are very close, thereby indicating a good fit. The adequate precision $(33.01,46.8517,41.7526)$ of the three models is greater than 4 , proving that the accuracy of the three models is sufficient and that they can be used in the navigation design space. The coefficient of variation (COV) is obtained by (6), which is used to indicate the credibility and accuracy of the models, and the unit is percentage. When the COV is less than $10 \%$, the test result is reliable. According to Table 13, the COV of the three response models is less than $10 \%$, thereby indicating that they are reliable and have good repeatability.

$$
\mathrm{COV}=\frac{100 *(\text { std.dev. })}{(\text { mean })}
$$

Figure 12 presents the normal distribution of the residuals of R1, R2, and R3, which can further determine model satisfaction. The larger the residual value, the worse the regression fitting effect, and the farther the deviation line of the points in the figure. The farther the point, the larger the deviation from the straight line. Figure 12 shows the data on the residual normal distribution maps of models R1, R2, and R3, which basically fall near the distribution fitting line; that is, the residual value is small and the fit is good, which further prove that the models can be used in the navigation design space. Moreover, the models can better describe the relationship between the three responses and two factors and provide highly accurate predictions.

\subsubsection{Interaction between Factors and Impact on Response.} Figure 13 illustrates the perturbation graph of each model. The perturbation graph in the RSM design reveals significant parameters by showing the change in the response value caused by the movement of each factor from the reference point, which is the zero coded level of each factor [28]. As one factor changes, the other factors remain unchanged at the reference value. In the three models, factor $A$ is steeper than factor $B$, thereby indicating that the compressive strength and flexural strength of the manufactured sand RPC are highly sensitive to the steel fiber content. As the steel fiber content $(A)$ increases, the three responses likewise increase. However, as the basalt fiber content $(B)$ increases, the three responses increase slowly and then decrease. An optimal content point exists, which also proves the above conclusion that only appropriate basalt fiber content can improve the compressive strength and flexural strength of the manufactured sand RPC, rather than the more the better.

Figure 14 demonstrates the contour and 3D graphs of the effects of the two factors of the steel fiber content $(A)$ and the basalt fiber content $(B)$ on the three responses, that is, $\mathrm{R} 1$, $\mathrm{R} 2$, and $\mathrm{R} 3$. In model $\mathrm{R} 1$, the contour of $A$ is denser than that of $B$, and the $3 \mathrm{D}$ graph is steep, as shown in Figure 14(a), thereby indicating that the influence of factor $A$ on response $\mathrm{R} 1$ is more obvious than that of factor $B$, which is the same as the previous conclusion. The bending degree of the $3 \mathrm{D}$ graph can represent the significant degree of interaction between the factors. The more curved the $3 \mathrm{D}$ graph, the more obvious 
TABLE 12: ANOVA results for response surface quadratic model parameters.

\begin{tabular}{|c|c|c|c|c|c|c|c|}
\hline Responses & Source & SOS & $\mathrm{DF}$ & MS & $F$-value & $P$ value & $R$ \\
\hline \multirow{9}{*}{ 28-day compressive strength $(R 1)$} & Model & 626.52 & 5 & 125.30 & 107.56 & $<0.0001$ & Sign. \\
\hline & A & 520.47 & 1 & 520.47 & 446.78 & $<0.0001$ & Sign. \\
\hline & $B$ & 28.85 & 1 & 28.85 & 24.76 & 0.0016 & Sign. \\
\hline & $A B$ & 30.80 & 1 & 30.80 & 26.44 & 0.0013 & Sign. \\
\hline & $A^{2}$ & 25.41 & 1 & 25.41 & 21.81 & 0.0023 & Sign. \\
\hline & $B^{2}$ & 27.03 & 1 & 27.03 & 23.20 & 0.0019 & Sign. \\
\hline & Residual & 8.15 & 7 & 1.16 & & & \\
\hline & Lack of fit & 5.84 & 3 & 1.95 & 3.36 & 0.1360 & Not sign. \\
\hline & Pure error & 2.32 & 4 & 0.5789 & & & \\
\hline \multirow{9}{*}{ 28-day flexural strength (R2) } & Model & 90.44 & 5 & 18.09 & 245.66 & $<0.0001$ & Sign. \\
\hline & A & 74.60 & 1 & 74.60 & 1013.12 & $<0.0001$ & Sign. \\
\hline & $B$ & 1.58 & 1 & 1.58 & 21.50 & 0.0024 & Sign. \\
\hline & $A B$ & 2.06 & 1 & 2.06 & 27.97 & 0.0011 & Sign. \\
\hline & $A^{2}$ & 11.33 & 1 & 11.33 & 153.83 & $<0.0001$ & Sign. \\
\hline & $B^{2}$ & 1.87 & 1 & 1.87 & 25.40 & 0.0015 & Sign. \\
\hline & Residual & 0.5154 & 7 & 0.0736 & & & \\
\hline & Lack of fit & 0.1229 & 3 & 0.0410 & 0.4176 & 0.7505 & Not sign. \\
\hline & Pure error & 0.3925 & 4 & 0.0981 & & & \\
\hline \multirow{9}{*}{ 28-day flexural-compressive ratio ( $R 3$ ) } & Model & 21.59 & 5 & 4.32 & 193.8 & $<0.0001$ & Sign. \\
\hline & A & 16.37 & 1 & 16.37 & 732.68 & $<0.0001$ & Sign. \\
\hline & $B$ & 0.1649 & 1 & 0.1649 & 7.38 & 0.0299 & Sign. \\
\hline & $A B$ & 0.2704 & 1 & 0.2704 & 12.10 & 0.0103 & Sign. \\
\hline & $A^{2}$ & 4.77 & 1 & 4.77 & 213.46 & $<0.0001$ & Sign. \\
\hline & $B^{2}$ & 0.1737 & 1 & 0.1737 & 7.77 & 0.0270 & Sign. \\
\hline & Residual & 0.1564 & 7 & 0.0223 & & & \\
\hline & Lack of fit & 0.0607 & 3 & 0.0202 & 0.8452 & 0.5365 & Not sign. \\
\hline & Pure error & 0.0957 & 4 & 0.0239 & & & \\
\hline
\end{tabular}

SOS: sum of squares; DF: degree of freedom; MS: mean square; $R$ : remark; Sign.: significant.

TABLE 13: Model validation for both responses.

\begin{tabular}{lccc}
\hline Statistical parameters & 28-day compressive strength (R1) & 28-day flexural strength (R2) & 28-day flexural-compressive ratio (R3) \\
\hline$R^{2}$ & 0.9872 & 0.9943 & 0.9928 \\
Adjusted $R^{2}$ & 0.9780 & 0.9903 & 0.9877 \\
Predicted $R^{2}$ & 0.9289 & 0.9836 & 0.9733 \\
Adeq. precision & 33.0126 & 46.8517 & 41.7526 \\
Std. dev. & 1.08 & 0.2713 & 0.1495 \\
Mean & 133.81 & 20.33 & 15.13 \\
COV (\%) & 0.8066 & 1.33 & 0.9880 \\
\hline
\end{tabular}

the interaction. In model $\mathrm{R} 1$, the significant degree of interaction between $A$ and $B$ is relatively high. When the steel fiber content $(A)$ is $1.44 \%, \mathrm{R} 1$ increases with the increase of the basalt fiber content $(B)$. When the steel fiber content $(A)$ is $3.56 \%, \mathrm{R} 1$ first increases and then slowly decreases with the increase of the basalt fiber content $(B)$. As shown in Figure 14(b), in model R2, the contour of $A$ is denser than that of $B$, the $3 \mathrm{D}$ graph is steep, and the interaction between $A$ and $B$ is relatively significant. When the steel fiber content $(A)$ is lower than $2.5 \%$, the increase of the basalt fiber content $(B)$ significantly improves $\mathrm{R} 2$. When the steel fiber content $(A)$ is high, the increase of the basalt fiber content $(B)$ has little effect on R2. As shown in Figure 14(c), the contour line of $A$ is denser than that of $B$, the $3 \mathrm{D}$ graph is steep, and the contour lines are approximately parallel; that is, the interaction between $A$ and $B$ is generally significant. When the steel fiber content $(A)$ is lower than $2.5 \%$, the increase of the basalt fiber content $(B)$ significantly improves R3. When the steel fiber content is high, the basalt fiber content $(B)$ has little influence on $\mathrm{R} 3$. These results can be attributed to the fact that when the steel fiber content is low, the small and multirooted basalt fibers are more likely to be evenly dispersed in various parts of the internal structure of the RPC, reducing the center spacing between the fibers and filling the gap between the steel fibers, which greatly increases the probability of bridging the internal cracks of RPC, hinders the generation of microcracks, and forms a better spatial network structure together with steel fibers, so the mechanical properties of RPC, especially the flexural performance, are significantly improved. When the steel fiber content is high, the excessive incorporation of basalt fiber will cause unfavorable phenomena such as entanglement and agglomeration of fibers, resulting in a reduction in the contact area between fiber and cementitious material, and 


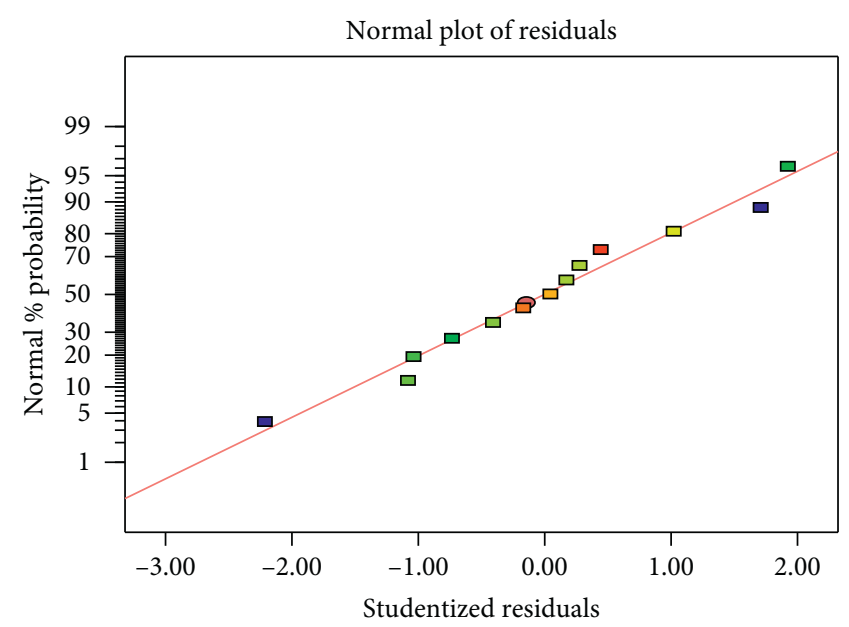

(a)

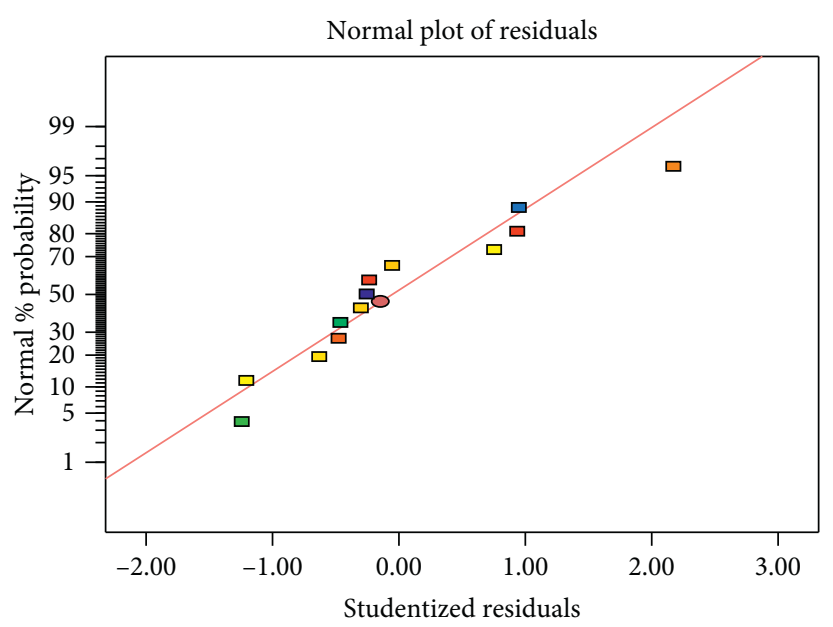

(b)

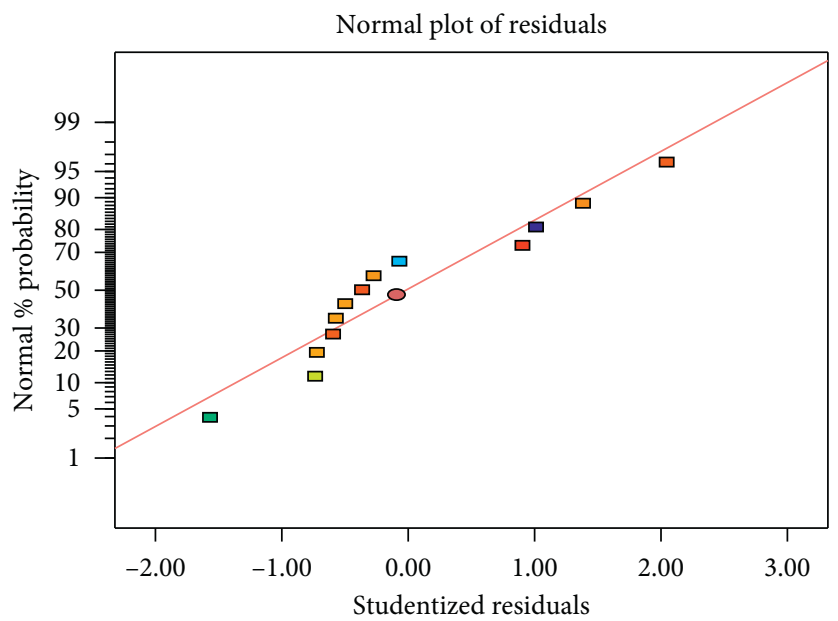

(c)

FIGURE 12: Normal distribution of residuals: (a) 28-day compressive strength (R1); (b) 28-day flexural strength (R2); (c) 28-day flexuralcompressive ratio (R3).

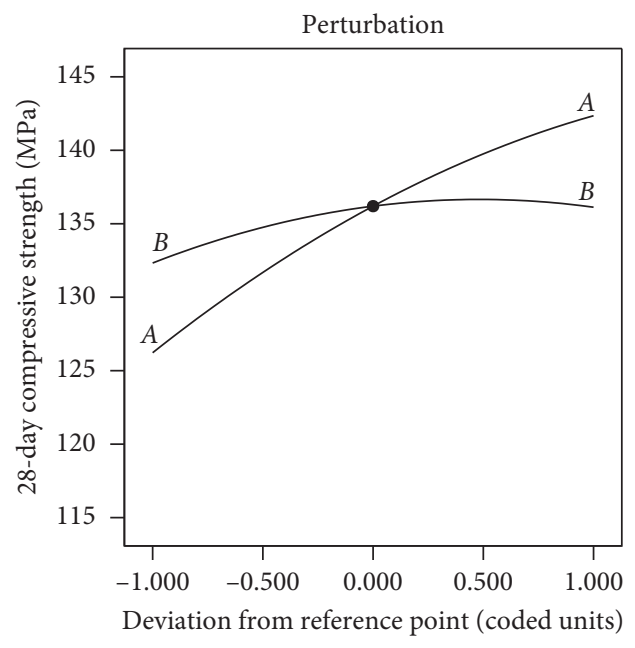

(a)

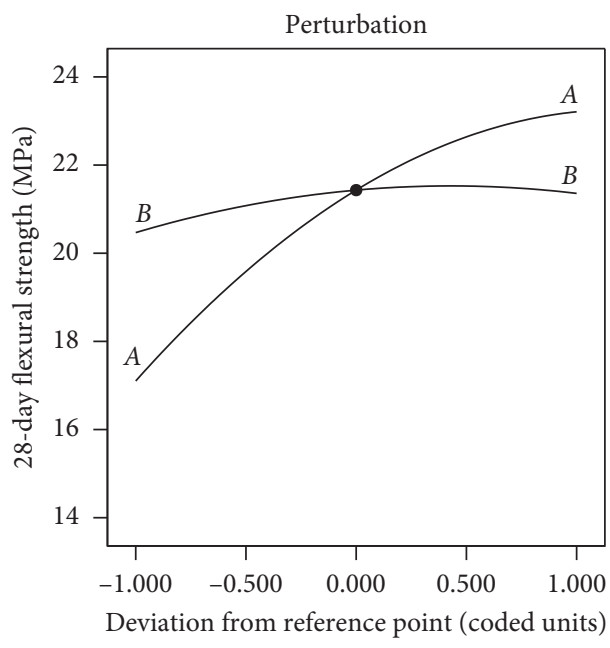

(b)

FIGURE 13: Continued. 


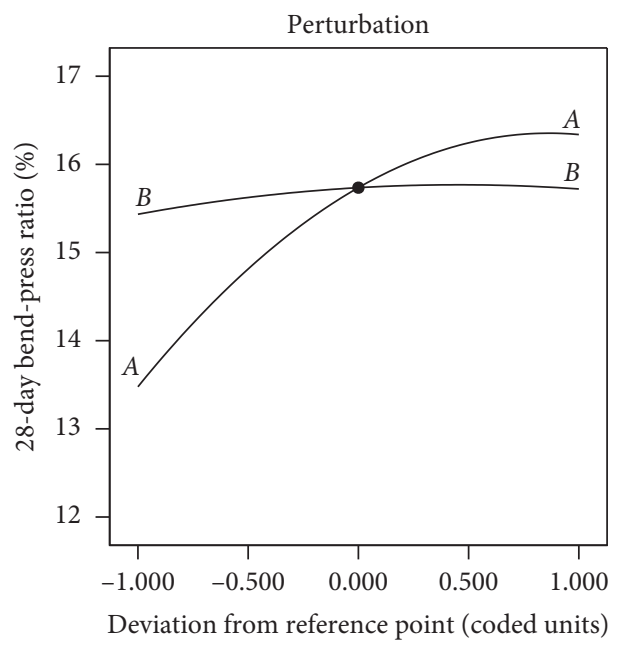

(c)

Figure 13: Perturbation plot for (a) 28-day compressive strength (R1); (b) 28-day flexural strength (R2); (c) 28-day flexural-compressive ratio (R3).

the weakening of the bond between fiber and matrix, affecting the compactness of the RPC matrix, increasing internal defects, reducing the effective internal bearing area of the material, and being detrimental to the improvement of the mechanical properties of RPC. In summary, basalt fiber mainly plays a role in inhibiting the beginning of microcracks, when the steel fiber hinders the development of cracks. Appropriate ratio of fiber mixing has a significant impact on the mechanical properties of manufactured sand $\mathrm{RPC}$ and increases the flexural-compressive ratio.

\section{Optimization of Fiber Content}

4.1. Content of the Two Fibers Optimized by RSM. Obtaining the maximum compressive strength, flexural strength, and flexural ratio simultaneously is difficult. Therefore, this study adopts multiobjective optimization technology to optimize multiple responses at the same time. In this study, compromise optimization is conducted for the 28-day compressive strength (R1), flexural strength (R2), and flexural-compressive ratio (R3). As mentioned above, the steel fiber content $(A)$ and basalt fiber content $(B)$ are the independent variables, and R1, R2, and R3 are the dependent variables. The RSM is adopted to find the optimal content of the two fibers to maximize the three response values. This study employs the process optimization function in the Design-Expert $8^{\circledR}$ software. The definitions of factors and responses during the optimization process are shown in Table 14. Each factor and response use the same important level. Based on the multiobjective optimization process, nine relatively close solutions are obtained, which meet the predetermined upper and lower limits. Desirability refers to the closeness of a response to a desired value, and the closer the value to 1 , the better. Figure 15 shows the changes in the desirability function based on the multiobjective optimization process. The desirability values are approximately 0.976 , which is close to 1 , thereby indicating that the RSM optimization technique is feasible. The largest group of desirability values is taken as the optimal group, and the optimal steel fiber content $(A)$ and basalt fiber content $(B)$ are $3.561 \%$ and $0.142 \%$, respectively. The predicted compressive strength, flexural strength, and flexural-compressive ratio are $119.51 \mathrm{MPa}, 23.25 \mathrm{MPa}$, and $16.36 \%$, respectively, as shown in Table 15 . The steel fiber content reaches $3.561 \%$, because the steel fiber content is the main influencing factor of each response of the manufactured sand RPC. The addition of steel fibers can inhibit the development of cracks and improve the mechanical properties of the manufactured sand RPC. However, the basalt fiber content is $0.142 \%$. Excessive basalt fiber content is not conducive to the overlap of steel fibers to cracks and will not improve the compressive strength and flexural strength of the manufactured sand RPC. Thus, the optimized basalt content is not excessive. Furthermore, additional tests are conducted to verify the theoretical response results. Three additional tests are conducted using the same mix ratio and two optimized fiber content to determine whether the optimized fiber content could provide improved compressive strength, flexural strength, and flexural-compressive ratio. Table 15 compares the average value of the three sets of experimental results with the theoretical response value. The results show that the average error between the theoretical response and actual response is $1.37 \%$, which is consistent. And through the slump test, it has been found that its workability is good. In other words, the above model can be used for practical prediction, and the optimal fiber content obtained by the RSM optimization process is accurate.

The compressive strength, flexural strength, and compression ratio obtained from the additional tests are 144.37 $\mathrm{MPa}, 23.09 \mathrm{MPa}$, and $16.02 \%$ compared with those of the H6 test group; the steel fiber content is reduced by $0.44 \%$; the basalt fiber content is reduced by $0.033 \%$; the compressive strength, flexural strength, and flexural-compressive ratio are similar; and the enhancement effect is obvious. This finding is 

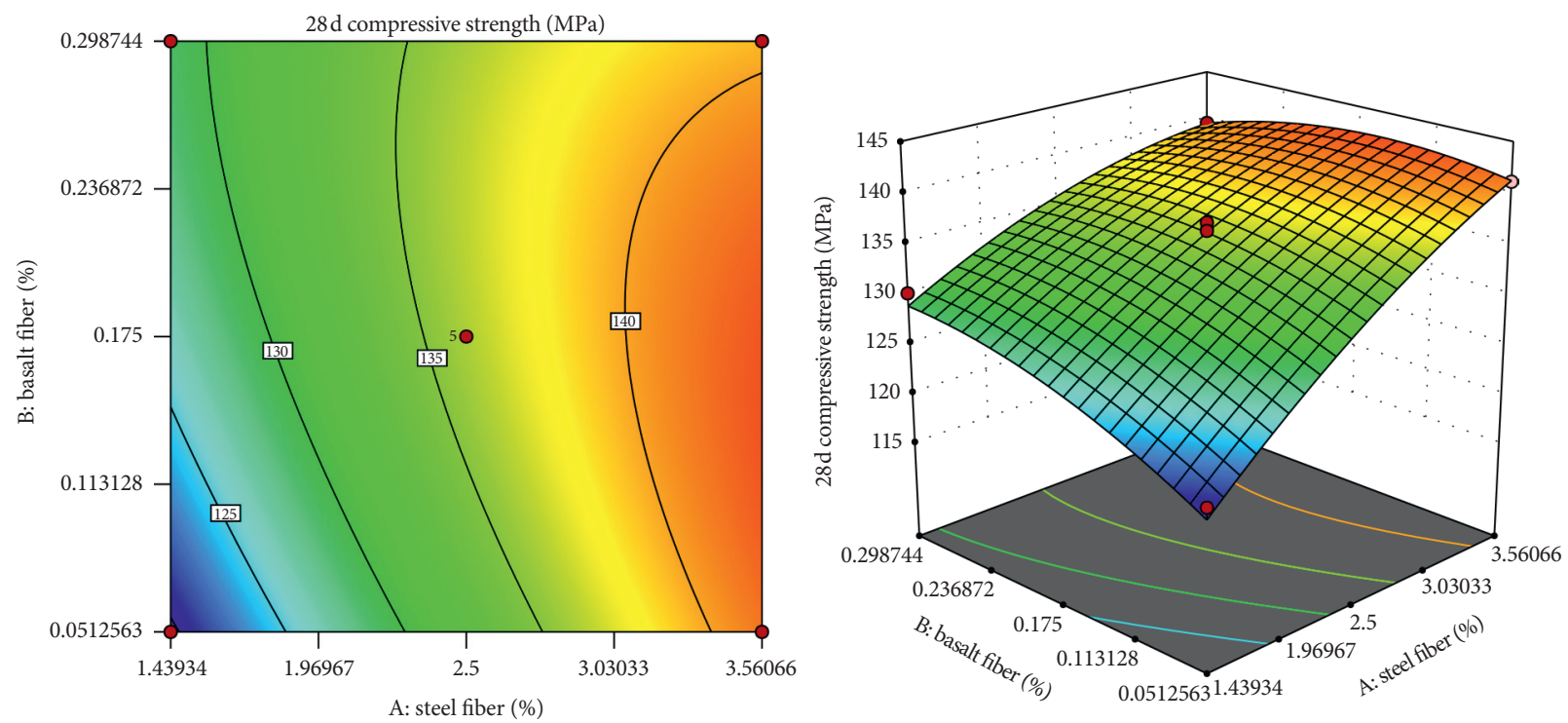

(a)
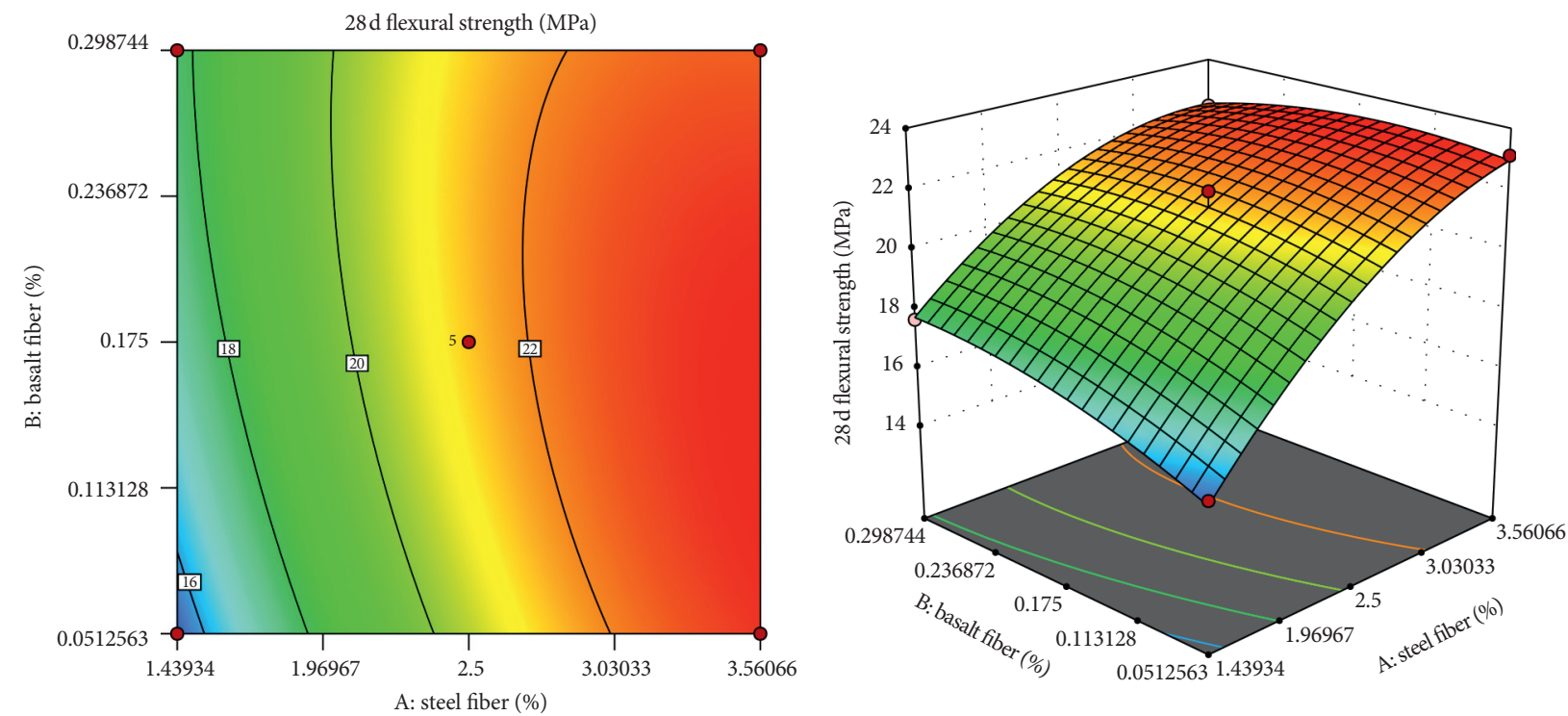

(b)

Figure 14: Continued. 

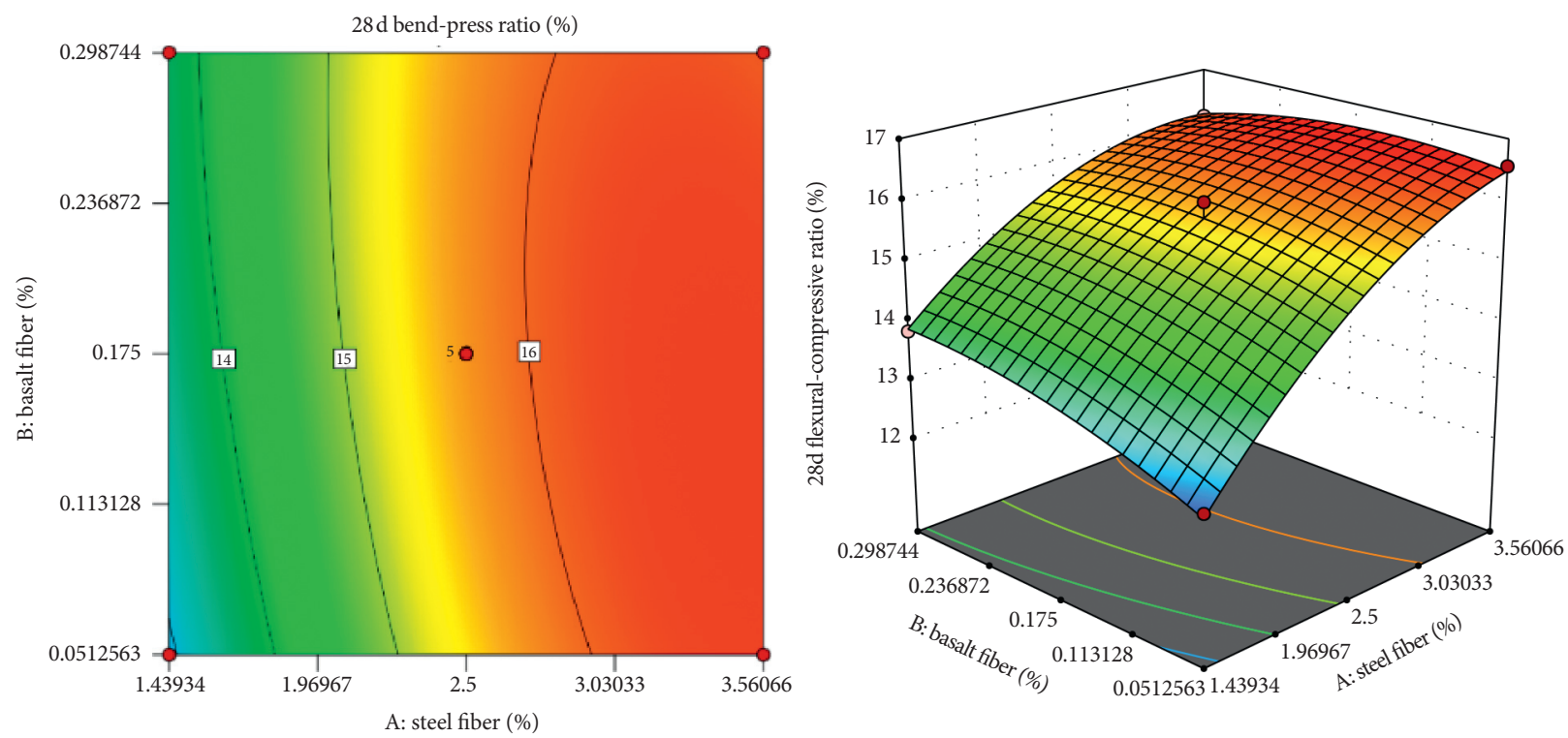

(c)

Figure 14: Contour and 3D plots: (a) R1; (b) R2; (c) R3.

TABLE 14: Definitions of factors and responses in the multiobjective optimization process.

\begin{tabular}{lccc}
\hline Factors and responses & Goal & Lower limit & Upper limit \\
\hline Steel fiber (\%) & In range & 1.44 & 3.56 \\
Basalt fiber (\%) & In range & 0.05 & 0.3 \\
Compressive strength (MPa) & Maximize & 119.51 & 144.08 \\
Flexural strength (MPa) & Maximize & 14.52 & 23.16 \\
Flexural-compressive ratio (\%) & Maximize & 12.15 & 16.38 \\
\hline
\end{tabular}

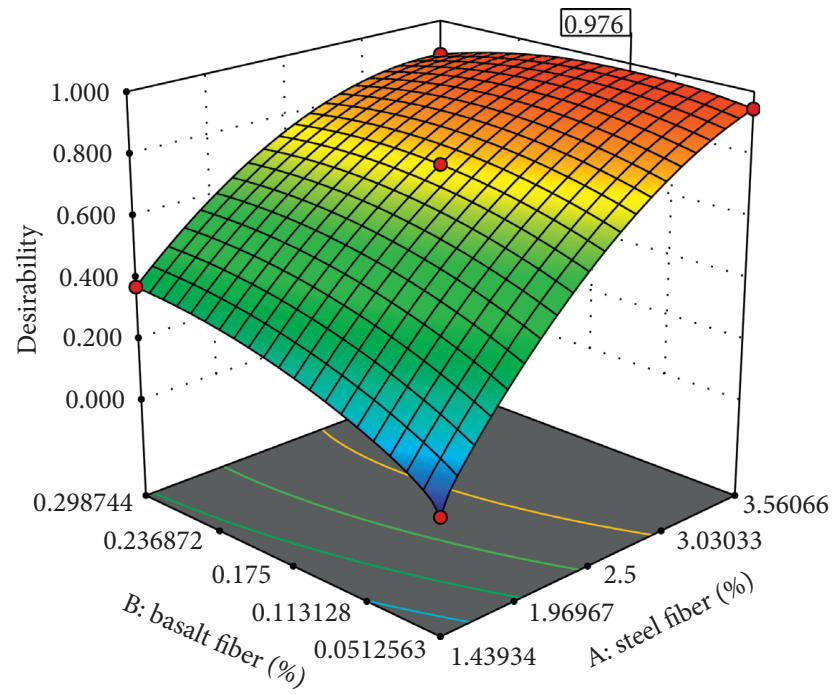

Figure 15: Variation in desirability function based on the multiobjective optimization process.

observed because the basalt fibers are mixed into the RPC and dispersed into very fine fiber filaments, which can be well inserted into the steel fibers in the mixture. However, once the steel fiber content becomes too large, staggered agglomeration occurs. Evenly distributing the basalt fibers between the steel fibers to work together is difficult, and the agglomerated mixed fibers tend to adsorb a large amount of cement mortar, thereby resulting in decreased strength. 
TABLE 15: Results of theoretical responses and additional experimental responses of optimal mix design.

\begin{tabular}{|c|c|c|c|}
\hline Factors and responses & Model predictive value & Actual test value & Error $(\%)$ \\
\hline Steel fiber (\%) & 3.561 & & \\
\hline Basalt fiber (\%) & 0.142 & & \\
\hline Compressive strength (MPa) & 142.45 & 144.37 & 1.35 \\
\hline Flexural strength $(\mathrm{MPa})$ & 23.25 & 23.09 & 0.69 \\
\hline Flexural-compressive ratio $(\%)$ & 16.36 & 16.02 & 2.08 \\
\hline Desirability & 0.976 & & \\
\hline
\end{tabular}

\section{Conclusions}

Based on the CCD in the RSM, this study conducts experimental research on the compressive strength, flexural strength, and workability of manufactured sand RPC mixed with steel and basalt fibers and draws the following conclusions:

(i) It is feasible to use manufactured sand instead of quartz sand and river sand to prepare RPC, and its 7-day and 28-day compressive strength and flexural strength are good under standard curing. The addition of steel fiber and basalt fiber slightly reduces the working performance of machine-made sand RPC, but its strength is improved, which can be used in actual engineering.

(ii) The mechanical properties of manufactured sand RPC mixed with steel and basalt fibers are improved substantially compared with those of manufactured sand RPC without fibers. When the steel fiber content is lower than $2.5 \%$, the influence of increasing the basalt content on flexural strength and flexural-compressive ratio is obvious. When the steel fiber content is too high, the addition of basalt fibers will have a negative mixing effect. The flexural-compressive ratio of steel-basalt fiber-manufactured sand RPC is much higher than that of ordinary concrete.

(iii) Three response surface models of 28-day compressive strength (R1), 28-day flexural strength (R2), and 28-day flexural-compressive ratio (R3) are established. ANOVA verifies that the three models have sufficient accuracy, and steel fibers are more significant than basalt fibers in improving the mechanical properties of machine-made sand RPC. In addition, the relationship equations between the three responses and the steel fiber content $(A)$ and basalt content $(B)$ are obtained to help select the desired steel and basalt fiber content of the manufactured RPC according to different actual conditions.

(iv) Based on the multiobjective optimization technology of the RSM, the optimal steel fiber content $(A)$ is $3.561 \%$, and the optimal basalt fiber content $(B)$ is $0.142 \%$. The predicted eclectic optimal 28-day compressive strength, 28-day flexural strength, and 28-day flexural-compressive ratio are $142.45 \mathrm{MPa}$, 23.25 $\mathrm{MPa}$, and $16.36 \%$, respectively. Additional tests verify that the optimal content obtained by RSM multiobjective optimization is reliable.

\section{Data Availability}

The data that supports the findings of this study are available within the article.

\section{Conflicts of Interest}

The authors declare no conflicts of interest.

\section{Authors' Contributions}

Y. Zhang and J. Liu contributed to conceptualization and methodology. J. Wang and J. Liu contributed to validation and formal analysis. Y. Zhang and J. Wang contributed to investigation and writing-review and editing. J. Liu and B. $\mathrm{Wu}$ contributed to writing-original draft preparation. J. Wang contributed to project administration.

\section{Acknowledgments}

This research was funded by the Science Technology Department Program of Jilin Province (Grant no. 20190303138SF), and the Science and Technology Project of Education Department of Jilin Province (Grant nos. JJKH20190875KJ and JJKH20190870KJ).

\section{References}

[1] P. Richard and M. Cheyrezy, "Composition of reactive powder concretes," Cement and Conssssscrete Research, vol. 25, no. 7, pp. 1501-1511, 1995.

[2] M. Cheyrezy, V. Maret, and L. Frouin, "Microstructural analysis of RPC (reactive powder concrete)," Cement and Concrete Research, vol. 25, no. 7, pp. 1491-1500, 1995.

[3] C. Zhong, M. Liu, Y. Zhang, and J. Wang, "Study on mix proportion optimization of manufactured sand RPC and design method of steel fiber content under different curing methods," Materials, vol. 12, no. 11, p. 1845, 2019.

[4] Y.-S. Tai, H.-H. Pan, and Y.-N. Kung, "Mechanical properties of steel fiber reinforced reactive powder concrete following exposure to high temperature reaching $800^{\circ} \mathrm{C}$," Nuclear Engineering and Design, vol. 241, no. 7, pp. 2416-2424, 2011.

[5] C. H. Dong and X. W. Ma, "Experimental research on mechanical properties of basalt fiber reinforced reactive powder concrete," Advanced Materials Research, vol. 893, pp. 610613, 2014.

[6] Saloma, Hanafiah, and F. N. Putra, "The effect of polypropylene fiber on mechanical properties of reactive powder concrete," AIP Conference Proceedings, vol. 1885, no. 1, Article ID 020093, 2017.

[7] Y. Ju, L. Wang, H. Liu, and G. Ma, "Experimental investigation into mechanical properties of polypropylene reactive 
powder concrete," ACI Materials Journal, vol. 115, no. 1, pp. 21-32, 2018.

[8] Y. Zhang, B. Wu, J. Wang, M. Liu, and X. Zhang, "Reactive powder concrete mix ratio and steel fiber content optimization under different curing conditions," Materials, vol. 12, no. 21, p. 3615, 2019.

[9] H. M. Al-Hassani, W. I. Khalil, and L. S. Danha, "Mechanical properties of reactive powder concrete with various steel fiber and silica fume contents," Acta Technica Corvininesis-Bulletin of Engineering, vol. 7, no. 1, 2014.

[10] K. Z. Ma, A. Que, and C. Liu, "Analysis of the influence of steel fiber content on mechanical properties of reactive powder concrete," Journal of Advanced Concrete Technology, vol. 3, pp. 76-83, 2016.

[11] F. Minelli and G. A. Plizzari, "On the effectiveness of steel fibers as shear reinforcement," ACI Structural Journal, vol. 110, no. 3, pp. 379-389, 2013.

[12] H. Liu, S. Liu, S. Wang, X. Gao, and Y. Gong, "Effect of mix proportion parameters on behaviors of basalt fiber RPC based on box-behnken model," Applied Sciences, vol. 9, no. 10, p. 2031, 2019.

[13] J. Branston, S. Das, S. Y. Kenno, and C. Taylor, "Mechanical behaviour of basalt fibre reinforced concrete," Construction and Building Materials, vol. 124, pp. 878-886, 2016.

[14] T. Ayub, N. Shafiq, and M. F. Nuruddin, "Mechanical properties of high-performance concrete reinforced with basalt fibers," Procedia Engineering, vol. 77, pp. 131-139, 2014.

[15] W. Liu, "Experimental study on basic mechanical properties and strengthening mechanism of steel fiber mixed basalt fiber reinforced cement mortar," Journal of Advanced Concrete Technology, vol. 12, pp. 125-128, 2013.

[16] Y. Wu, L. Chen, and W. Li, "Experimental study on mechanical properties of steel-basalt hybrid fiber pavement concrete," International Journal of Science Technology and Engineering, vol. 15, pp. 232-238, 2015.

[17] Z.-X. Li, C.-H. Li, Y.-D. Shi, and X.-J. Zhou, "Experimental investigation on mechanical properties of hybrid fibre reinforced concrete," Construction and Building Materials, vol. 157, pp. 930-942, 2017.

[18] GB175-2007, Standard for Common Portland Cement, Chinese Standard, Beijing, China, 2007.

[19] GB/T51003/2014, Technical Code for Application of Mineral Admixture, Chinese Standard, Beijing, China, 2014.

[20] JGJ 52-2006, Standard for Technical Requirements and Test Method of Sand and Rrushed Stone (or Gravel) for Ordinary Concrete, Ministry of Construction of the People's Republic of China, Beijing, China, 2015.

[21] GB/T31387-2015, Standard for Reactive Powder Concrete, Chinese Standard, Beijing, China, 2015.

[22] GB/T50080-2002, Standard Test Methods for Performance of Ordinary Concrete Mixtures, Chinese Standard, Beijing, China, 2007.

[23] N. Biglarijoo, M. Nili, S. M. Hosseinian, M. Razmara, S. Ahmadi, and P. Razmara, "Modelling and optimisation of concrete containing recycled concrete aggregate and waste glass," Magazine of Concrete Research, vol. 69, no. 6, pp. 306-316, 2017.

[24] M. A. A. Aldahdooh, N. M. Bunnori, and M. A. M. Johari, "Evaluation of ultra-high-performance-fiber reinforced concrete binder content using the response surface method," Materials \& Design (1980-2015), vol. 52, pp. 957-965, 2013.

[25] D. C. Montgomery, Design and Analysis of Experiments, John Wiley \& Sons, Hoboken, NJ, USA, 2017.
[26] M. Barbuta, E. Marin, S. M. Cimpeanu et al., "Statistical analysis of the tensile strength of coal fly ash concrete with fibers using central composite design," Advances in Materials Science and Engineering,vol. 2015, Article ID 486232, 7 pages, 2015.

[27] L. Jiang and J. Yin, "A brief discussion on the factors affecting concrete bend-press ratio," Journal of Ready-Mixed Concrete, vol. 7, pp. 51-55, 2018.

[28] T. F. Awolusi, O. L. Oke, O. O. Akinkurolere, and A. O. Sojobi, "Application of response surface methodology: predicting and optimizing the properties of concrete containing steel fibre extracted from waste tires with limestone powder as filler," Case Studies in Construction Materials, vol. 10, Article ID e00212, 2019. 